\title{
PLGA nanoparticles codeliver paclitaxel and Stat3 siRNA to overcome cellular resistance in lung cancer cells
}

This article was published in the following Dove Press journal:

International Journal of Nanomedicine

2 August 2012

Number of times this article has been viewed

\author{
Wen-Pin Su ${ }^{1,2}$ \\ Fong-Yu Cheng ${ }^{3}$ \\ Dar-Bin Shieh ${ }^{3-6}$ \\ Chen-Sheng Yeh ${ }^{5-7}$ \\ Wu-Chou Su ${ }^{1,2,8}$ \\ 'Graduate Institute of Clinical \\ Medicine, College of Medicine, \\ National Cheng Kung University; \\ ${ }^{2}$ Department of Internal Medicine, \\ National Cheng Kung University \\ Hospital, College of Medicine, \\ National Cheng Kung University; \\ ${ }^{3}$ Institute of Oral Medicine, College \\ of Medicine, National Cheng \\ Kung University; ${ }^{4}$ Department of \\ Stomatology, National Cheng Kung \\ University Hospital, College of \\ Medicine, National Cheng Kung \\ University; ${ }^{5}$ Advanced Optoelectronic \\ Technology Center; ${ }^{6}$ Center for \\ Frontier Materials and Micro/ \\ Nano Science and Technology, \\ and ${ }^{7}$ Department of Chemistry, \\ National Cheng Kung University; \\ ${ }^{8}$ Cancer Center, National Cheng \\ Kung University Hospital, College \\ of Medicine, National Cheng Kung \\ University, Tainan, Taiwan.
}

Correspondence: Wu-Chou Su Department of Internal Medicine, National Cheng Kung University Hospital, College of Medicine, National Cheng Kung University, 35 Xiaodong Road,

Tainan 704, Taiwan

Tel +886 62353535 ext 3107

Fax +88662766175

Email sunnysu@mail.ncku.edu.tw

Chen-Sheng Yeh

Department of Chemistry, National

Cheng-Kung University, I University

Road, Tainan 704, Taiwan

Tel +886 62757575 ext 65328

Email csyeh@mail.ncku.edu.tw
Abstract: Background: Effective cancer chemotherapy remains an important issue in cancer treatment, and signal transducer and activator of transcription-3 (Stat3) activation leads to cellular resistance of anticancer agents. Polymers are ideal vectors to carry both chemotherapeutics and small interfering ribonucleic acid (siRNA) to enhance antitumor efficacy. In this paper, poly(lactic-co-glycolic acid) (PLGA) nanoparticles loaded with paclitaxel and Stat3 siRNA were successfully synthesized, and their applications in cancer cells were investigated.

Methods: Firstly, paclitaxel was enclosed by PLGA nanoparticles through solvent evaporation. They were then coated with cationic polyethylenimine polymer (PLGA-PEI-TAX), enabling it to carry Stat3 siRNA on its surface through electrostatic interactions (PLGA-PEI-TAX-S3SI). The size, zeta potential, deliver efficacy, and release profile of the PLGA nanocomplexes were characterized in vitro. The cellular uptake, intracellular nanoparticle trajectory, and subsequent cellular events were evaluated after treatment with various PLGA nanocomplexes in human lung cancer A549 cells and A549-derived paclitaxel-resistant A549/T12 cell lines with $\alpha$-tubulin mutation.

Results: A549 and A549/T12 cells contain constitutively activated Stat3, and silencing Stat3 by siRNA made both cancer cells more sensitive to paclitaxel. Therefore, PLGA-PEI-TAXS3SI was synthesized to test its therapeutic role in A549 and A549/T12 cells. Transmission electron microscopy showed the size of PLGA-PEI-TAX-S3SI to be around $250 \mathrm{~nm}$. PLGAPEI nanoparticles were nontoxic. PLGA-PEI-TAX was taken up by A549 and A549/T12 cells more than free paclitaxel, and they induced more condensed microtubule bundles and had higher cytotoxicity in these cancer cells. Moreover, the yellowish fluorescence observed in the cytoplasm of the cancer cells indicates that the PLGA-PEI nanoparticles were still simultaneously delivering Oregon Green paclitaxel and cyanine-5-labeled Stat3 siRNA 3 hours after treatment. Furthermore, after the cancer cells were incubated with the synthesized PLGA nanocomplexes, PLGA-PEI-TAX-S3SI suppressed Stat3 expression and induced more cellular apoptosis in A549 and A549/T12 cells compared with PLGA-PEI-TAX.

Conclusion: The PLGA-PEI-TAX-S3SI complex provides a new therapeutic strategy to control cancer cell growth.

Keywords: PLGA, nanoparticle, paclitaxel, siRNA, simultaneous drug delivery

\section{Introduction}

Lung cancer is a major cause of cancer death worldwide. Drug resistance to anticancer treatment is an important issue where advances in cisplatin-based chemotherapy and targeted therapy have significantly increased the tumor control rate. ${ }^{1}$ Targeted therapy that blocks only one of these pathways allows the other pathways to act as salvage or escape mechanisms for cancer cells. ${ }^{2}$ A logical approach involves target agents 
that decrease both drug resistance and survival signals, ie, a targeted agent combined with chemotherapy to improve treatment efficacy in lung cancer. ${ }^{2}$

Signal transducer and activator of transcription (Stat) proteins are latent cytoplasmic transcription factors that regulate cell proliferation, migration, and differentiation. ${ }^{3,4}$ In the Stat family, Stat3 regulates genes that encode apoptosis inhibitors, cell cycle regulators, and inducers of angiogenesis., ${ }^{4,5}$ Downregulation of Stat 3 decreases cell viability and increases apoptosis in cancer cells. ${ }^{6}$ Overexpression of Stat3 leads to chemoresistance. ${ }^{7}$ Therefore, targeting Stat 3 may provide an efficient way to enhance treatment efficacy in lung cancer.

Currently, small interfering ribonucleic acid (siRNA) technology provides new types of drugs that are easy to design and have high target selectivity to inhibit specific gene expression in the cytoplasm. The major limitations in the therapeutic use of siRNA are their rapid degradation in cellular cytoplasm and their easy excretion from the kidney. ${ }^{8,9}$ Furthermore, siRNA molecules have poor cellular uptake and poor tissue specificity. ${ }^{8,9}$ Hence, an ideal vector for siRNA delivery is needed to prevent their excretion from the kidney and increase their cellular uptake.

Polymers provide a platform for carrying chemotherapeutics and siRNA simultaneously to exert significant enhancement in antitumor efficacy. ${ }^{10,11}$ The United States Food and Drug Administration approved the polymer poly(lactic-co-glycolic acid) (PLGA) for human use. The final product of PLGA using cellular metabolic conversion is water and carbon dioxide in a tricarboxylic acid cycle, and thus is recognized to be nontoxic. ${ }^{12}$ Many studies have demonstrated that PLGA nanoparticles (NPs) enter the cell efficiently through specific and nonspecific endocytosis. ${ }^{13}$ Intracellular-retained PLGA NPs can release the encapsulated drug slowly leading to a sustained drug effect. ${ }^{14}$

Many stabilizers such as polyvinyl alcohol, polyvinyl pyrrolidone, and Tween ${ }^{\circledR} 80$ are added to prevent PLGA NP aggregation during PLGA NP preparation. ${ }^{15,16}$ These stabilizers significantly limit their biomedical application because they do not have functional groups for further modifications. Synthesizing stabilizer-free and biodegradable PLGA NPs was previously successful when significant amounts of drugs could be encapsulated in PLGA NPs $<100 \mathrm{~nm}$ in diameter. ${ }^{17,18}$ One advantage of PLGA NPs is that they can be directly coated with cationic polymers, such as polyethylenimine (PEI), enabling them to carry siRNA on their surfaces through electrostatic interactions. ${ }^{19,20}$ Therefore, PLGA-PEI NPs could be used as a carrier that integrates anticancer drugs (inner part) and agents to reduce chemoresistance, eg, siRNA (outer layer).

This study demonstrates that PLGA-PEI NPs provide a platform for the codelivery of paclitaxel and Stat3 siRNA. The approach provides a new strategy to overcome tumor drug resistance.

\section{Material and methods Antibodies and reagents}

The following antibodies were used: anti-Stat3 (Tyr705), antiStat1, anti- $\alpha$-tubulin (Cell Signaling Technology, Beverly, MA), anti-Stat3 (Santa Cruz Biotechnology, Santa Cruz, CA), and anti-actin (Chemicon International Inc, Pittsburgh, PA). Paclitaxel and PEI polymer (average molecular weight $25 \mathrm{kDa}$ ) were from Sigma-Aldrich Corporation (St Louis, MO), Oregon Green ${ }^{\circledR} 488$ paclitaxel was from Molecular Probes ${ }^{\circledR}$ Life Technologies (Carlsbad, CA), and PLGA copolymer (5050 DLG 4.5A; molecular weight $66 \mathrm{kDa}$ ) was from Evonik Industries AG (Darmstadt, Germany). All reagents were purchased from Sigma-Aldrich.

\section{Cell lines}

Human lung cancer cell line A549 and A549-derived paclitaxel-resistant A549/T12 cell lines with $\alpha$-tubulin mutation were obtained from Dr Susan Horwitz (Department of Molecular Pharmacology, Albert Einstein College of Medicine, Bronx, NY). ${ }^{21}$ All cell culture-related reagents were purchased from Gibco ${ }^{\circledR}$ Life Technologies.

\section{siRNA}

Human siRNA targeting Stat3 messenger RNA labeled with cyanine-5 (Cy5) was purchased from Ambion ${ }^{\circledR}$ Life Technologies (sense: 5'-GGAUCUAGAACAGAAAAUGTT-3', antisense: 5'-CAUUUUCUGUUCUAGAUCCTG-3'). The scrambled control for Stat3 siRNA was purchased from Applied Biosystems ${ }^{\mathrm{TM}}$ Life Technologies. Tumor cells were transfected with Stat3 siRNA or scrambled control using Lipofectamine $^{\mathrm{TM}} 2000$ (Invitrogen ${ }^{\mathrm{TM}}$ Life Technologies) for Stat 3 silencing and evaluated after 48 hours.

\section{Preparation of PLGA-PEI NPs for the codelivery of paclitaxel and Stat3 siRNA}

The surfactant-free manufacturing process for encapsulating paclitaxel into PLGA NPs was as follows: $1 \mathrm{mg}$ of paclitaxel and $50 \mathrm{mg}$ of PLGA copolymer were dissolved in $5 \mathrm{~mL}$ acetone. The acetone solution of PLGA-paclitaxel was precooled for 10 minutes at $4^{\circ} \mathrm{C}$ and titrated dropwise (360 $\mu \mathrm{L} /$ minute) with a 50/50 (volume/volume) ethanol/ 
water solution using a peristaltic pump (MasterFlex $\mathrm{C} / \mathrm{L}$ Model:77122-22). The titrated solution was homogenized using ultrasonication (Branson S8500, Emerson Electric (Taiwan) Co. Ltd) $(2000 \mathrm{~W})$ at $4^{\circ} \mathrm{C}$, making the nonstabilized premicelles (entanglements of PLGA and paclitaxel) evenly distributed during formation. This process continued until it became slightly turbid or translucent so that the premicelles in the system reached critical micelle concentration (critical level). The titrated mixture was transferred into a glass beaker containing $20 \mathrm{~mL}$ cold sterile Milli- $\mathrm{Q}^{\circledR}$ water (Millipore Corporation, Billerica, MA) forming a white colloid solution. This colloid solution was placed under ultrasonication for 15 minutes at $4^{\circ} \mathrm{C}$ stabilizing the PLGA micellar NPs. The existing acetone in the white colloid solution was removed by vacuum evaporation using 15-minute ultrasonication at $4^{\circ} \mathrm{C}$. Finally, the evaporated colloid solution was filtrated using 40- $\mu \mathrm{m}$ nylon mesh (BD Falcon cat \# 352340) to avoid aggregation of the PLGA NPs. Using an ultravioletvisible spectrum (Hewlett-Packard Model 8453) (absorption wavelength: $270 \mathrm{~nm}$ ), loading efficacy (\%) was determined by comparing the amount of nonencapsulated paclitaxel in the supernatant with the initial paclitaxel concentration. PEI $(0.3 \mathrm{mg} / \mathrm{mL})$ was added to paclitaxel-loaded PLGA NPs (20:100 volume/volume percent) to create PEI-coated paclitaxel-loaded PLGA NPs (PLGA-PEI-TAX), which was dissolved in $5 \mathrm{~mL}$ acetone. PLGA-PEI-TAX was washed with phosphate buffered saline (PBS) after 30 minutes of ultrasonication. Then, $0.5 \mu \mathrm{g}$ Stat3 siRNA (PLGA-PEITAX-S3SI) or Cy5-labeled Stat3 siRNA (PLGA-PEI-TAXCy5-S3SI) was added for 30 minutes at room temperature. PLGA-PEI-TAX-S3SI or PLGA-PEI-TAX-Cy5-S3SI was harvested as a pellet with resuspension in PBS buffer ( $\mathrm{pH} 7.4$ ) after 10 minutes of centrifugation at 13,000 rpm. By Fluorescence spectrophotometer (F-2500, HITACHI) detecting Cy5 fluorescence (excitation 649 nm/emission $670 \mathrm{~nm}$ ), the delivery efficacy of Cy5 siRNA was determined by comparing the amount of Cy5 siRNA in the supernatant with the initial amount of Cy5 siRNA.

\section{PLGA-PEI NP characterization}

Electron micrographs of PLGA NPs and PLGA-PEI-S3SI were carried out by placing a drop of the sample onto copper mesh coated with an amorphous carbon film, (Ted Pella Inc, 79725 ) and dried in a vacuum desiccator. (Thermo Scientific Nalgene Vacuum Desiccator, EW-06520-05) PLGA NPs were stained with phosphotungstic acid before transmission electron microscopy (TEM) (PHILIPS CM-200) at 200KV images were taken. The mean diameter and morphology of
PLGA NPs, PLGA-PEI NPs, PLGA-PEI-TAX, PLGA-PEIS3SI, and PLGA-PEI-TAX-S3SI were characterized by TEM. The hydrodynamic size of all NPs in PBS (pH 7.4) was also determined by dynamic light scattering (DLS) instruments in triplicate at room temperature (Zetasizer ${ }^{\circledR}$ Nano $3000 \mathrm{HS}$ Advanced; Malvern Instruments Inc, Malvern, United Kingdom). The surface potential of various PLGA NPs was determined by their zeta potential (Zetasizer).

\section{In vitro release studies}

PLGA-PEI NPs carrying fluorescent material such as PLGAPEI NPs loaded with Oregon Green paclitaxel (excitation 488 nm/emission 535 nm; PLGA-PEI-Ore TAX) or PLGAPEI-Cy5-S3SI (excitation $649 \mathrm{~nm} /$ emission $670 \mathrm{~nm}$ ) was added into a 1.5-mL Eppendorf tube (Eppendorf, Hamburg, Germany) containing PBS buffer ( $1 \mathrm{~mL}, 10 \mathrm{~mm}, \mathrm{pH}$ 7.4). Supernatant containing fluorescent material from the PLGA NPs was collected by 10-minute centrifugation at 13,000 rpm after specific time intervals. A control experiment (acetone was added to dissolve the PLGA NPs) was performed to determine the fluorescent intensity of the PLGA NPs. The percentage of fluorescent material released at each time point was determined by a F-2500, HITACHI fluorescence spectrophotometer.

\section{Western blotting analysis}

Cells were harvested and finally resuspended using a whole cell extraction solution (0.02 M 4-[2-hydroxyethyl]1-piperazineethanesulfonic acid, $\mathrm{pH} 7.9 ; 0.005 \%$ nonyl phenoxypolyethoxyethanol; $0.15 \%$ glycerol; $0.3 \mathrm{M}$ sodium chloride; 0.001 M ethylenediaminetetraacetic acid; and 0.01 M sodium fluoride) with cocktail protease inhibitors (Roche Diagnostics GmbH, Mannheim, Germany). Lysates were collected by centrifugation after 30 minutes on ice. Protein concentrations were estimated by the Bradford method. Protein $(50 \mu \mathrm{g})$ from cell lysates was resolved using sodium dodecyl sulfate polyacrylamide gel electrophoresis (BIORAD, Mini-PROTEAN Tetra Cell and PowerPac Basic Power Supply \#165-8025) and transferred onto polyvinylidene fluoride membranes (Millipore). The membranes were probed with antibodies specific for the proteins of interest. Enhanced chemiluminescence (GE Healthcare, Arlington Heights, IL) was used to develop blots.

\section{Microtubule assembly assay}

Cells at a density of $10^{6} / 100 \mathrm{~mm}^{2}$ dish were treated with indicated concentrations of paclitaxel, PLGA-PEI-TAX, and PLGA-PEI-TAX-S3SI for 24 hours. Cells were washed three 
times with PBS buffer before adding lysis buffer containing $20 \mathrm{mM}$ tris(hydroxymethyl)aminomethane-hydrogen chloride (pH 6.8), 1 mM magnesium chloride, 2 mM ethylene glycol tetraacetic acid, $1 \mathrm{mM}$ phenylmethylsulfonyl fluoride, $1 \mathrm{mM}$ orthovanadate, $0.5 \%$ nonyl phenoxypolyethoxyethanol, and $20 \mathrm{mg} / \mathrm{mL}$ proteinase inhibitors (aprotinin, leupeptin, and pepstatin). The supernatant was collected after 10 minutes of centrifugation at $15,000 \mathrm{rpm}$ at $4^{\circ} \mathrm{C}$. This resulted in soluble tubulin dimers in the supernatant and polymerized microtubules in the pellet. Equal amounts of the two fractions were partitioned on a protein basis by sodium dodecyl sulfate polyacrylamide gel electrophoresis. Immunoblots were probed with $\alpha$-tubulin monoclonal antibody. $^{22}$

\section{Cytotoxicity assay}

Cytotoxicity was determined by 3-(4,5-dimethylthiazol-2yl)-2,5-diphenyl tetrazolium bromide assay. Initially, $1 \times 10^{5}$ cancer cells were grown in a 96-well tissue culture plate. Cells were treated with individual agents in different concentrations for another 48 hours after growing for 24 hours. One-tenth of the original culture volume of the 3-(4,5-dimethylthiazol2-yl)-2,5-diphenyl tetrazolium bromide stock solution was added to each culture and then incubated for 4 hours at $37^{\circ} \mathrm{C}$. The medium was removed after centrifugation and dimethyl sulfoxide was added, dissolving the formazan dye. A microplate reader (Thermo Scientific Multiskan EX, 51118177) measured the absorbance at a wavelength of $490 \mathrm{~nm}$. The cytotoxicity induced by each treatment was calculated as the percentage of viability, which was determined by dividing the optical density values in the drug-treated wells by those in the control wells.

\section{Annexin V-fluorescein isothiocyanate apoptosis study}

Asynchronous cultures were set for experiments $\left(2 \times 10^{5}\right.$ cells in six-well plates). Individual wells were treated with free paclitaxel, PLGA-PEI-TAX, and PLGA-PEI-TAX-S3SI for 24 hours. The cells were stained according to the manufacturer's instructions with Annexin V-fluorescein isothiocyanate and propidium iodine staining assay kit (Invitrogen) and measured by flow cytometry (BD FACSCalibur System, BD Biosciences, San Jose, CA).

\section{Confocal images}

Cancer cells were cultured, trypsinized, and seeded in four-well chamber slides $\left(10^{4}\right.$ cells/well). Each well was washed with PBS buffer twice and cells were treated with free paclitaxel, Oregon Green paclitaxel, or various PLGAPEI NPs at an indicated time after 24 hours of incubation. Cells were fixed by $4 \%$ paraformaldehyde/PBS for 1 hour at room temperature. The slides were incubated with or without anti-Stat3, anti-Stat1, or anti- $\alpha$-tubulin antibodies (dilution $1: 25$ ) overnight at $4^{\circ} \mathrm{C}$. Incubation with secondary antibodies conjugated to antimouse Alexa Fluor ${ }^{\circledR} 488$ and antirabbit Alexa Fluor 594 (Invitrogen) was performed for an indirect immunofluorescence assay. Nuclei were visualized by 4,6-diamidino-2-phenylindole staining (Sigma-Aldrich). A laser (excitation 405, 488, 594, or $649 \mathrm{~nm}$ ) and a scanning confocal microscope (Fluoview ${ }^{\circledR}$ FV-1000; Olympus Corporation, Tokyo, Japan) detected fluorophores.

\section{Determination of intracellular Oregon Green paclitaxel}

Cancer cells $\left(5 \times 10^{4}\right)$ were seeded into a 96-well plate and treated with $62.5 \mathrm{nM}$ Oregon Green paclitaxel or the equivalent amount of drug loaded into PLGA-PEI NPs for 72 hours. As per Meng et al, ${ }^{23}$ intracellular Oregon Green paclitaxel fluorescence was measured at an excitation/ emission wavelength of $485 / 538 \mathrm{~nm}$ with a microplate reader after the cells were washed with cold PBS.

\section{Statistical analysis}

IBM $^{\circledR}$ SPSS 13.0 software (SPSS Inc, Chicago, IL) was used to analyze the data. The cancer cell lines study presents the differences between two independent nonnormal distributed groups using the Mann-Whitney U test. Statistical significance was set at $P<0.05$.

\section{Results}

\section{Stat 3 activation leads to chemoresistance in lung cancer cells}

Human lung cancer A549 cells and its paclitaxel-resistant derivative-A549/T12 cells contain activated Stat3 (Figure 1A). ${ }^{21}$ The half maximal inhibitory concentration was $62.6 \mathrm{nM}$ in A549 cells and $320.3 \mathrm{nM}$ in A549/T12 cells when A549 and A549/T12 cells were treated with paclitaxel for 48 hours. Therefore, A549 cells were more sensitive to paclitaxel than A549/T12 cells (Figure 1A). Stat3 silencing using siRNA sensitized the two cells to paclitaxel in A549 and A549/T12 cells, suggesting that Stat 3 activation contributes to cellular resistance to paclitaxel in these two lung cancer cells (Figure 1B). 
A
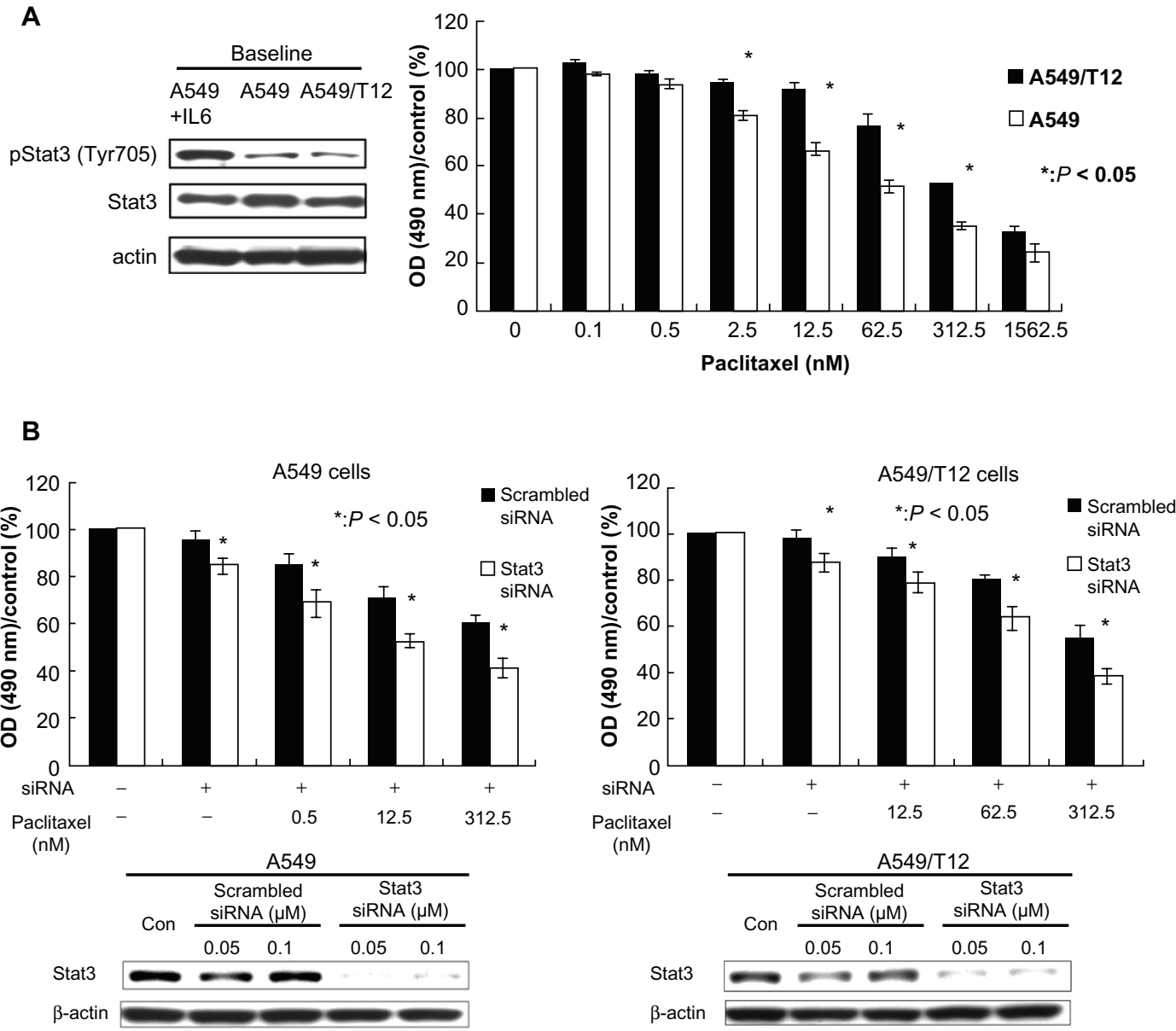

Figure I Constitutively activated signal transducer and activator of transcription-3 (Stat3) in cancer cell lines: parental A549 and A549-derived paclitaxel-resistant A549/ TI2. (A) Analysis of baseline tyrosine-activated and total Stat3 protein in A549 and A549/TI 2 cells. The protein extract from A549 cells after treatment with 10 ng/mL interleukin- 6 was used as the positive control for activated Stat3 protein for 30 minutes. $\beta$-actin protein was used as the loading control. Cell viability was assessed by 3-(4,5-dimethylthiazol-2-yl)-2,5-diphenyl tetrazolium bromide assay after paclitaxel treatment at various dosages (0.1 nM, $0.5 \mathrm{nM}, 2.5 \mathrm{nM}, 12.5 \mathrm{nM}, 62.5 \mathrm{nM}, 3$ I $2.5 \mathrm{nM}$, and $1562.5 \mathrm{nM}$ ) for 48 hours. Each experiment was repeated three times. (B) Stat3 expression was examined after exposure of A549 and A549/TI 2 cells to $0.05 \mu$ M or $0.1 \mu M$ scrambled small interfering ribonucleic acid or Stat3 small interfering ribonucleic acid for 48 hours with or without paclitaxel treatment at various dosages (A549 cells: $0.5 \mathrm{nM}$, $12.5 \mathrm{nM}$, and $312.5 \mathrm{nM}$; A549/TI 2 cells: $12.5 \mathrm{nM}, 62.5 \mathrm{nM}$, and $312.5 \mathrm{nM})$. $\beta$-actin protein was used as the loading control. Cell viability was assessed by 3-(4,5-dimethylthiazol2-yl)-2,5-diphenyl tetrazolium bromide assay. Each experiment was repeated three times.

Abbreviations: OD, optical density; siRNA, small interfering ribonucleic acid; Stat3, signal transducer and activator of transcription-3.

\section{Synthesis and characteristics of PLGA-PEI-TAX-S3SI}

To synthesize PLGA-PEI-TAX-S3SI, paclitaxel was encapsulated into PLGA NPs. Then, the surface of paclitaxel-loaded PLGA NPs was coated with PEI (positive charge). Finally, Stat3 siRNA (negative charge) were carried on the surface of PLGA-PEI-TAX by electrical attraction.

Table 1 summarizes the average diameter and zeta potential of various PLGA NPs. Measured using TEM, spherical PLGA NPs were observed to be around $80 \mathrm{~nm}$ (Figure 2A). The NPs significantly increased in size when either PEI was attached to the surface of PLGA NPs or when PLGA-PEI NPs carried Stat 3 siRNA. NP size was slightly larger when measured by DLS compared to TEM measurements (Table 1). The final diameter of PLGA-PEI-TAX-S3SI was around $250 \mathrm{~nm}$ and $300 \mathrm{~nm}$ using TEM and DLS, respectively (Table 1). The zeta potential of PLGA NPs was negatively charged, which became positive when PEI was coated onto the surface of PLGA NPs. PLGA-PEI NPs carrying either paclitaxel or Stat3 siRNA did not significantly alter zeta potential. Finally, PLGA-PEI-TAX-S3SI displayed a positive net surface charge (Table 1).

PLGA NPs were stained with phosphotungstic acid to enhance the contrast between PEI and PLGA components and observed using TEM. The surface coating of the PEI-siRNA layer (indicated by arrows) occupied the outer surface of the 
Table I Average diameter and zeta potential of poly(lactic-coglycolic acid) nanoparticles

\begin{tabular}{|c|c|c|c|c|c|c|}
\hline & \multicolumn{4}{|c|}{ Particle size $(\mathrm{nm})$} & \multirow{2}{*}{\multicolumn{2}{|c|}{$\begin{array}{l}\text { Zeta } \\
\text { potential } \\
(\mathrm{mV})\end{array}$}} \\
\hline & \multicolumn{2}{|l|}{ TEM } & \multicolumn{2}{|l|}{ DLS } & & \\
\hline & Mean & SD & Mean & SD & Mean & SD \\
\hline PLGA NPs & 86.6 & 6.8 & 95.3 & 7.3 & -35.7 & 7.8 \\
\hline PLGA-PEI & 196.4 & 10.2 & 223 & 10.3 & 53.6 & 9.8 \\
\hline PLGA-PEI-S3SI & 234.5 & 11.4 & 270.8 & 11.2 & 46.2 & 7.1 \\
\hline PLGA-PEI-TAX & 202.1 & 11.3 & 230.5 & 9.4 & 51.2 & 8.1 \\
\hline PLGA-PEI-TAX-S3SI & 248.6 & 12.4 & 295.3 & 14.6 & 40.8 & 6.6 \\
\hline
\end{tabular}

Abbreviations: DLS, dynamic light scattering; PLGA-PEI, poly(lactic-co-glycolic acid)-polyethylenimine nanoparticles; PLGA-PEI-S3SI, poly(lactic-co-glycolic acid)polyethylenimine nanoparticles loaded with signal transducer and activator of transcription-3 small interfering ribonucleic acid; PLGA-PEI-TAX-S3SI, poly(lacticco-glycolic acid)-polyethylenimine nanoparticles loaded with paclitaxel and signal transducer and activator of transcription-3 small interfering ribonucleic acid; PLGA NPs, poly(lactic-co-glycolic acid) nanoparticles; SD, standard deviation; TEM, transmission electron microscopy.

PLGA NPs, but the distribution was mildly inhomogeneous (Figure 2A).

\section{Delivery efficacy and release profile of the PLGA nanocomplex}

The drug loading of PLGA-PEI-TAX was determined by comparing the initial amount of paclitaxel with the amount of nonencapsulated paclitaxel using an ultraviolet-visible spectrum (absorption wavelength: $270 \mathrm{~nm}$ ). By detecting Cy5 fluorescence (excitation $649 \mathrm{~nm} / \mathrm{emission} 670 \mathrm{~nm}$ ), the delivery efficacy of Cy5 siRNA by PLGA NPs was determined by comparing the amount of Cy5 siRNA in the supernatant with the initial amount of Cy5 siRNA. The drug loading of PLGA-PEI-TAX and PLGA-PEI-Cy5-S3SI was $2.43 \%$ and $32.1 \%$, respectively. There was no difference between PLGAPEI NPs loaded with and without paclitaxel in the delivery efficacy for Cy5 siRNA (Table 2).

PLGA-PEI-Ore TAX and PLGA-PEI-Ore TAX-Cy5S3SI were added to PBS buffer ( $\mathrm{pH} 7.4$ ) to examine their release profile. Fluorescence intensity in the supernatant was detected at each time point. The initial burst release of fluorescent Oregon Green paclitaxel was around $20 \%$ within the first 3 hours and 35\% within 24 hours from PLGA-PEI-Ore TAX followed by sustained release, which was up to $50 \%$ after 96 hours (Figure 2B and C). In addition, the initial burst release of Cy5 siRNA was around $50 \%$ within the first 3 hours and $75 \%$ within 24 hours from PLGA-PEI-Ore TAX-Cy5-S3SI followed by sustained release, which was more than $80 \%$ after 96 hours (Figure 2B and D).
Therefore, Cy5 siRNA was released from PLGA-PEIOre TAX-Cy5-S3SI first and Oregon Green paclitaxel, initially, was stably encapsulated inside the NPs and then gradually released. The release profile of fluorescent paclitaxel was not significantly influenced by adding siRNA onto the surface of PLGA-PEI-Ore TAX. The Cy5 siRNA release rate was similar between PLGAPEI NPs loaded with and without paclitaxel (Figure 2C and D).

\section{A549 and A549/TI 2 cells were more sensitive to PLGA NPs loaded with paclitaxel than free paclitaxel alone}

PLGA-PEI NPs (6 ng of PEI per $1 \mu \mathrm{g}$ of PLGA) were nontoxic to A549 and A549/T12 cells (Figure 3A). A549/ T12 cells were more resistant to paclitaxel than A549 cells (Figure 1A). However, PLGA-PEI-TAX became more cytotoxic to both A549 and A549/T12 cells than paclitaxel alone (Figure 3A).

Paclitaxel is well known to induce microtubule stabilization. A549/T12 cells have an $\alpha$-tubulin mutation compared to A549 cells. ${ }^{21}$ Indirect fluorescence assay and confocal microscopy was used to demonstrate the change in cellular $\alpha$-tubulin during PLGA-PEI-TAX treatment. The density of cellular tubulin in A549 cells was more compact at baseline than in A549/T12 cells. Paclitaxel increased the density of microtubules and promoted the formation of long, thick microtubule bundles 3 hours after treatment. Figure 3B shows the comparison of the cellular baseline in A549 and A549/T12 cells. Three hours after treatment with PLGA-PEI-TAX, both A549 and A549/T12 cells became smaller and irregular in shape, which tended to be due to apoptosis (Figure 3B). Hence, PLGA-PEI-TAX was more cytotoxic to lung cancer cells than free paclitaxel.

\section{The effect of PLGA-PEI-S3SI in A549 and A549/TI 2 cells}

The intracellular Stat3 expression in A549 and A549/ T12 cells was only silenced by PLGA-PEI-S3SI when scrambled siRNA or Stat3 siRNA was carried by PLGA-PEI NPs (Figure 4A). Downregulation of Stat3 using PLGAPEI-S3SI led to cell death in these two cancer cells. Indirect fluorescence assay and confocal microscopy were used to demonstrate the intracellular effect of PLGA-PEI-S3SI. Stat3 and Stat 1 were indicated by green and red fluorescence, 
A

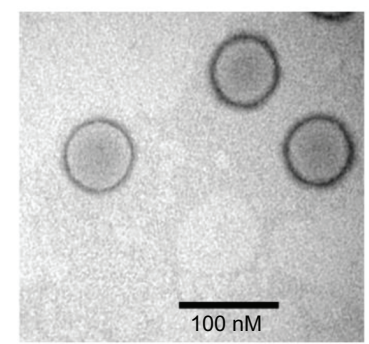

PLGA NPs

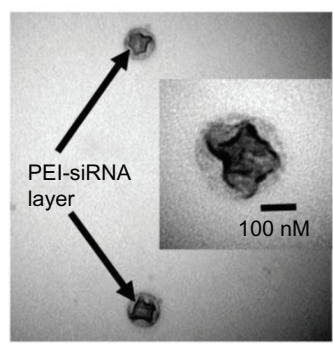

PLGA-PEI-siRNA-NPs

B
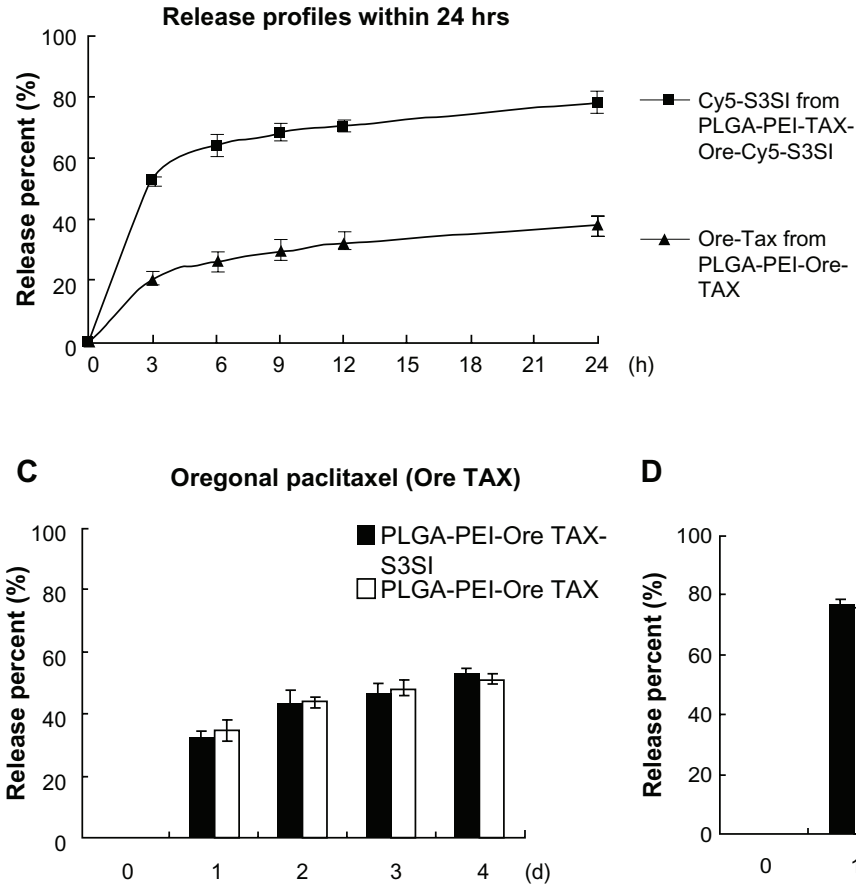

D

Cy5-Stat3 siRNA

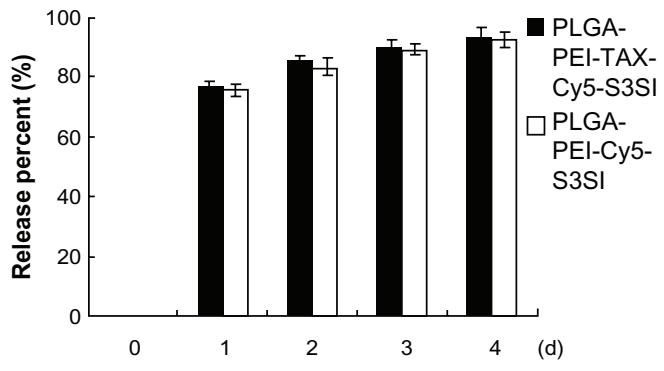

Figure 2 Characteristics of poly(lactic-co-glycolic acid) (PLGA) nanoparticles. (A) Representative transmission electron micrographs featuring PLGA nanoparticles and PLGA-polyethylenimine (PEI) nanoparticles loaded with signal transducer and activator of transcription-3 (Stat3) and small interfering ribonucleic acid (siRNA); siRNA was carried at the outer layer of the PLGA-PEI nanoparticles loaded with siRNA (marked with arrows). Scale bars represent I00 nm. (B) The release percent of encapsulated Oregon Green paclitaxel from PLGA-PEI nanoparticles loaded with Oregon Green paclitaxel and cyanine-5 siRNA from PLGA-PEI loaded with Oregon Green paclitaxel and cyanine-5-labeled Stat3 siRNA were measured in phosphate buffered saline several times within 24 hours (3, 6, 9, 12, and 24 hours) using a fluorescence spectrophotometer. The experiment was performed three times. (C) The release percent of encapsulated Oregon Green paclitaxel from PLGA-PEI nanoparticles loaded with Oregon Green paclitaxel and PLGA-PEI nanoparticles loaded with Oregon Green paclitaxel and Stat3 siRNA was measured in phosphate buffered saline each day using a fluorescence spectrophotometer. The experiment was performed three times. (D) The release percent of cyanine-5 siRNA from PLGA-PEI nanoparticles loaded with cyanine-5-labeled Stat3 siRNA and PLGA-PEI nanoparticles loaded with Oregon Green paclitaxel and cyanine-5-labeled Stat3 siRNA was measured in phosphate buffered saline each day. The experiment was performed three times.

Abbreviations: h, hours; NPs, nanoparticles; PLGA, poly(lactic-co-glycolic acid); PLGA-PEI-Cy5-S3SI, poly(lactic-co-glycolic acid)-polyethylenimine nanoparticles loaded with cyanine-5-labeled signal transducer and activator of transcription-3 small interfering ribonucleic acid; PLGA-PEI-Ore TAX, poly(lactic-co-glycolic acid)-polyethylenimine nanoparticles loaded with Oregon Green paclitaxel; PLGA-PEI-Ore TAX-S3SI, poly(lactic-co-glycolic acid)-polyethylenimine nanoparticles loaded with Oregon Green paclitaxel and signal transducer and activator of transcription-3 small interfering ribonucleic acid; PLGA-PEI-S3SI, poly(lactic-co-glycolic acid)-polyethylenimine nanoparticles loaded with signal transducer and activator of transcription-3 small interfering ribonucleic acid; PLGA-PEI-siRNA, poly(lactic-co-glycolic acid)-polyethylenimine nanoparticles loaded with small interfering ribonucleic acid; PLGA-PEI-TAX-Cy5-S3SI, poly(lactic-co-glycolic acid)-polyethylenimine nanoparticles loaded with paclitaxel and cyanine-5-labeled signal transducer and activator of transcription-3 small interfering ribonucleic acid.

respectively, in A549 and A549/T12 cells. Stat3 protein colocalized with Stat1 protein (indicated by yellowish fluorescence). Yellowish fluorescence appeared more in the nucleus than in the cytoplasm in A549/T12 cells compared to A549 cells. This might indicate that there were more nuclei
Stat3 proteins in A549/T12 cells than in A549 cells. Only red fluorescence (Stat1) was retained in these two cancer cells when Stat3 protein was suppressed by PLGA-PEI-S3SI, which indicates that only Stat 3 expression was specifically downregulated by PLGA-PEI-S3SI (Figure 4B). 
Table 2 Drug delivery efficacy of poly(lactic-co-glycolic acid)polyethylenimine nanoparticles

\begin{tabular}{lll}
\hline & \multicolumn{2}{l}{ Drug delivery efficacy $(\%)$} \\
\cline { 2 - 3 } & Mean & SD \\
\hline PLGA-PEI-TAX & 2.43 (TAX) & 0.23 \\
PLGA-PEI-Cy5-S3SI & 32.1 (siRNA) & 3.5 \\
PLGA-PEI-TAX-Cy5-S3SI & 29.5 (siRNA) & 4 \\
\hline
\end{tabular}

Abbreviations: PLGA-PEI-TAX, poly(lactic-co-glycolic acid)-polyethylenimine nanoparticles loaded with paclitaxel; PLGA-PEI-Cy5-S3SI, poly(lactic-co-glycolic acid)-polyethylenimine nanoparticles loaded with cyanine-5-labeled signal transducer and activator of transcription-3 small interfering ribonucleic acid; PLGA-PEI-TAXCy5-S3SI, poly(lactic-co-glycolic acid)-polyethylenimine nanoparticles loaded with paclitaxel and cyanine-5-labeled signal transducer and activator of transcription-3 small interfering ribonucleic acid; SD, standard deviation; siRNA, small interfering ribonucleic acid; TAX, paclitaxel.

\section{Demonstration of PLGA-PEI-Ore TAX-Cy5- S3SI taken up by A549 and A549/TI 2 cells}

PLGA-PEI-TAX-S3SI was synthesized to reduce chemoresistance with Stat3 siRNA followed by paclitaxel killing the cancer cells.

A549 and A549/T12 cells were treated with PLGAPEI-Ore TAX for 3 hours. Using confocal microscopy, it was found that Oregon Green paclitaxel (greenish fluorescence) was retained in the cytoplasm in A549 and A549/T12 cells (Figure 5A). In addition, more intense greenish fluorescence was seen in A549 and A549/T12 cells treated with PLGA-PEI-Ore TAX than free Oregon Green paclitaxel (Figure 5A). The intracellular uptake of free Oregon Green paclitaxel was improved by delivering the drug via PLGA-PEI NPs in A549 and A549/T12 cells (Figure 5B). There was no difference in the intracellular uptake of Oregon Green paclitaxel between A549 and A549/ T12 cells (Figure 5B).

The greenish fluorescence of Oregon Green paclitaxel accumulating in the perinuclear cytoplasmic area in both cancer cells was observed when A549 and A549/T12 cells were treated with PLGA-PEI-Ore TAX-Cy5-S3SI for 3 hours (Figure 5C). The majority of the reddish fluorescence of Cy5-Stat3 siRNA was retained in the cytoplasm. Some reddish fluorescence appeared in the nucleus and was more evident in A549/T12 cells than in A549 cells (Figure 5C). This indicates that 3 hours after PLGA-PEIOre TAX-Cy5-S3SI treatment in A549 and A549/T12 cells, some Cy5-Stat3 siRNA was released from the PLGA-PEI NPs and went into the nucleus (Figure 5C). Furthermore, yellowish fluorescence was found in the cytoplasm in both A549 and A549/T12 cells, indicating that there were still many PLGA-PEI NPs simultaneously delivering Oregon Green paclitaxel and Cy5-Stat3 siRNA in the cytoplasm 3 hours after treatment (Figure 5C).

\section{PLGA-PEI-TAX-S3SI effectively kills A549} and $A 549 / T 12$ cells

A549 and A549/T12 cells were treated for 48 hours with free paclitaxel, PLGA-PEI-TAX, and PLGA-PEI-TAX-S3SI. Cellular survival and Stat3 expression was evaluated. PLGAPEI-TAX-S3SI was able to downregulate Stat3 expression and had the most cellular toxicity in both A549 and A549/ T12 cells (Figure 6A).

The effect of free paclitaxel, PLGA-PEI-TAX, and PLGA-PEI-TAX-S3SI on microtubule polymerization was explored. PLGA-PEI-TAX and PLGA-PEI-TAX-S3SI induced more microtubule aggregation than free paclitaxel. PLGA-PEI-TAX and PLGA-PEI-TAX-S3SI had a similar effect on microtubules in A549 cells. However, PLGA-PEITAX-S3SI-induced tubule aggregation was mildly attenuated in A549/T12 cells compared with A549 cells (Figure 6B).

The mechanism of cell death induced by PLGA-PEITAX-S3SI was studied using Annexin V and propidium iodine double staining. It was found that PLGA-PEI-TAX induced more cellular apoptosis in A549 and A549/T12 cells compared to free paclitaxel. PLGA-PEI-TAX-S3SI regulated Stat3 expression, enhancing cellular apoptosis and early necrosis in response to treatment in both A549 and A549/ T12 cells compared to PLGA-PEI-TAX (Figure 6C). Conclusively, PLGA-PEI NPs are an ideal platform for the simultaneous delivery of paclitaxel and Stat 3 siRNA because it is able to overcome cellular resistance to paclitaxel.

\section{Discussion}

Silencing Stat3 reduced cellular resistance to paclitaxel in A549 cells and its paclitaxel-resistant A549/T12 cells. It has been demonstrated that PLGA-PEI NPs is a carrier for drug delivery. ${ }^{17,18}$ Accordingly, PLGA-PEI-TAX-S3SI was developed to improve cancer treatment. More PLGA-PEIOre TAX NPs were taken up by A549 and A549/T12 cells compared to free Oregon Green paclitaxel. Treating these two cancer cells with PLGA-PEI-TAX increased microtubule aggregation and led to more cell death. PLGA-PEI-Ore TAX-Cy5-S3SI was directly seen in A549 and A549/ T12 cells using confocal microscopy. Treating cancer cells with PLGA-PEI-TAX-S3SI could suppress Stat3 expression, leading towards more apoptosis and early necrosis. Hence, a nanovector provides a platform for the integration of anticancer drugs and agents to decrease chemoresistance and then enhance treatment efficacy. ${ }^{10,11}$

NPs with a smaller mean diameter have a lower loading efficacy and faster paclitaxel release due to shorter diffusion paths and larger surface areas. ${ }^{24,25}$ The loading efficacy of 
A

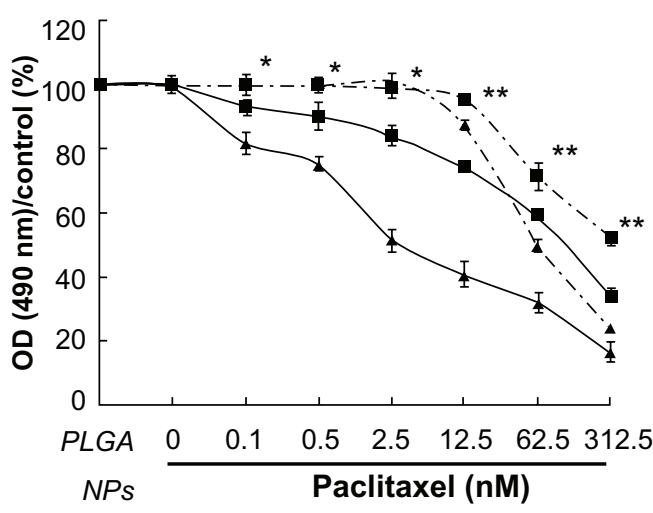

B
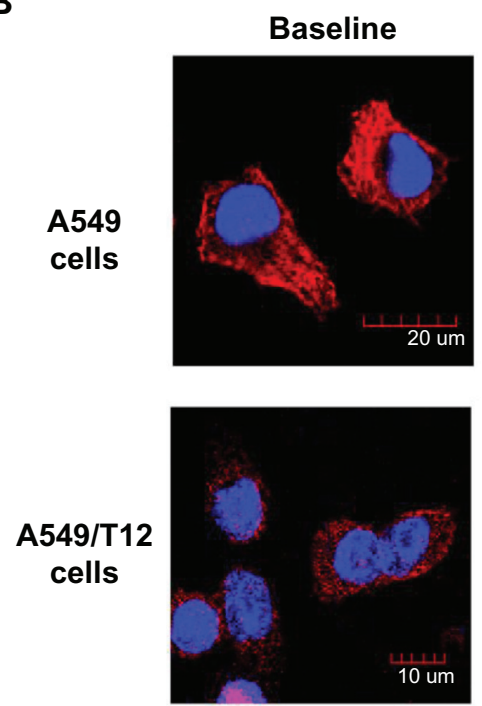

Paclitaxel
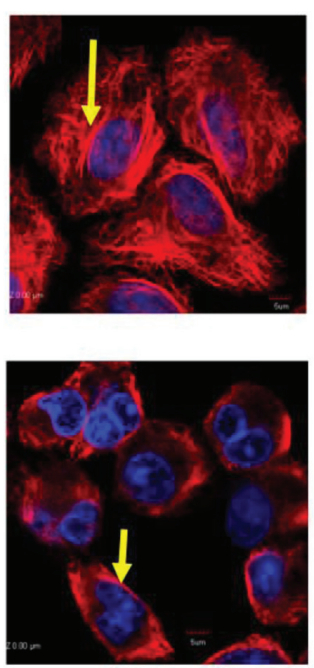

A549/T12

-4- A549/T12-PLGA-

PEI-TAX

- A549

- A549-PLGA-PEI-

TAX

**: $P<0.05$ (paclitaxel versus

PLGA-PEI-Tax) in A549

and A549/T12 cells

*: $P<0.05$ (paclitaxel versus

PLGA-PEI-Tax) in A549 cells

Figure 3 Poly(lactic-co-glycolic acid)-polyethylenimine nanoparticles loaded with paclitaxel (PLGA-PEI-TAX) was more cytotoxic to A549 and A549/TI2 cells than free paclitaxel alone. (A) Cellular viability was assessed by 3-(4,5-dimethylthiazol-2-yl)-2,5-diphenyl tetrazolium bromide assay when A549 and A549/TI2 cells were treated with PLGA nanoparticles and PLGA-PEI nanoparticles for 48 hours. Cells were treated with paclitaxel and PLGA-PEI-TAX at various dosages (0.I nM, 0.5 nM, 2.5 nM, I2.5 nM, $62.5 \mathrm{nM}$, and $312.5 \mathrm{nM}$ ) in A549 cells and TI2 cells for 48 hours. (B) Cellular $\alpha$-tubulin (red) was blotted by immunostaining and subsequent confocal microscopy 3 hours after A549 cells were treated with $12.5 \mathrm{nM}$ of paclitaxel and $12.5 \mathrm{nM}$ of PLGA-PEI-TAX, respectively. The same experiment was performed with $62.5 \mathrm{nM}$ of paclitaxel and $62.5 \mathrm{nM}$ of PLGA-PEI-TAX in A549/TI2 cells.

Notes: The nucleus is shown by $4^{\prime}, 6$-diamidino-2-phenylindole staining. Tubulin aggregation is marked with arrows. Scale bar is $5 \mu \mathrm{m}$.

Abbreviations: NPs, nanoparticles; OD, optical density; PLGA, poly(lactic-co-glycolic acid); PLGA-PEI-TAX, poly(lactic-co-glycolic acid)-polyethylenimine nanoparticles loaded with paclitaxel.

paclitaxel into polyester NPs (around $180 \mathrm{~nm}$ in diameter) is about $1 \%-4 \%$ using the oil-to-water emulsion solvent evaporation method. ${ }^{26}$ Therefore, the loading efficacy of the PLGA NPs $(2.43 \%)$ had an acceptable profile and it is reasonable to assume that PLGA-PEI-TAX-S3SI was able to exert an anticancer effect in the current study.

When PLGA-PEI NPs are used as a therapeutic carrier to simultaneously deliver paclitaxel (inner part) and Stat3 siRNA (outer layer), the potential cytotoxicity of PEI is a concern. PEI with a higher molecular weight (ie, $25 \mathrm{kDa}$ ) shows high cytotoxicity and transfection efficiency, whereas PEI with a lower molecular weight (ie, $1.8 \mathrm{kDa}$ ) shows low cytotoxicity and transfection efficiency. ${ }^{27} \mathrm{Ten} \mu \mathrm{g} / \mu \mathrm{L}$ of PEI (ie, $25 \mathrm{kDa}$ ) has been shown to be toxic to cells. ${ }^{28}$ Consistent with Patil and Panyam's observation, ${ }^{29}$ the current study showed that PLGA-PEI NPs (PEI molecular weight $25 \mathrm{kDa}$ ) did not induce significant toxicity due to the low concentration of PEI in the formulation ( $6 \mathrm{ng} / \mu \mathrm{g}$ of PLGA).

In accordance with Meng et al, ${ }^{23}$ the distribution of the PEIsiRNA layer occupying the outer surface of PLGA particle was mildly inhomogeneous, as shown by TEM observation. However, the slightly inhomogeneous distribution of the PEI-siRNA layer did not influence the treatment effect of PLGA-PEI-TAX-S3SI in the current study. 

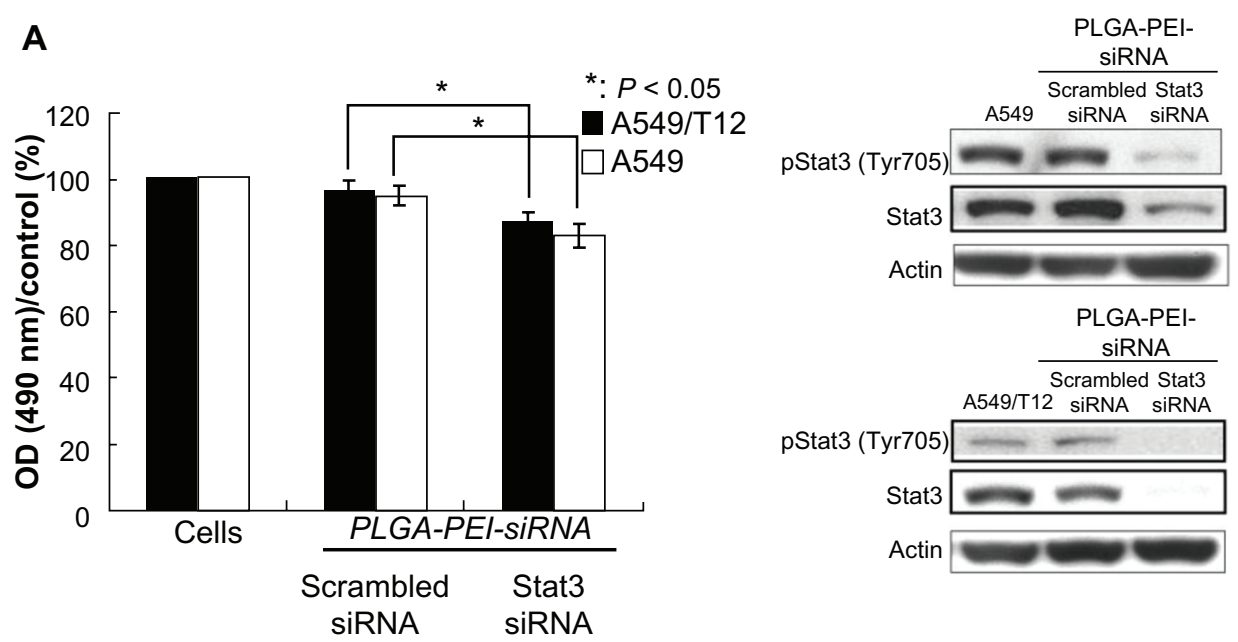

B
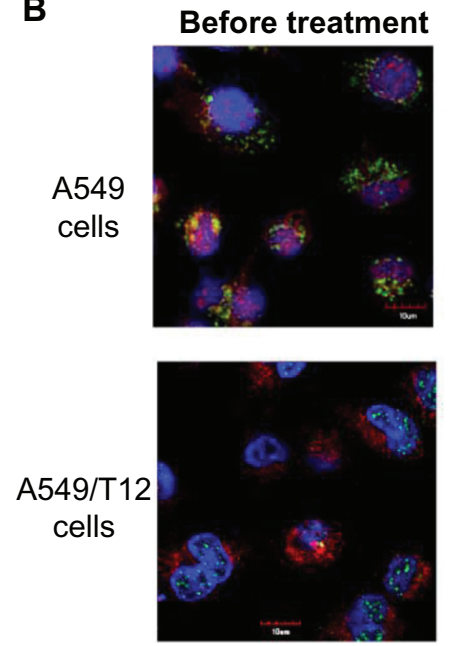

\section{PLGA-PEI-S3SI}
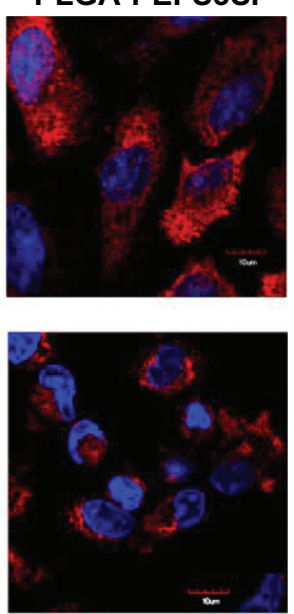

Green: Stat3 protein

Red: Stat1 protein

Blue: nucleus

Figure 4 Poly(lactic-co-glycolic acid)-polyethylenimine nanoparticles loaded with signal transducer and activator of transcription-3 (Stat3) small interfering ribonucleic acid (siRNA) effectively suppressed Stat3 protein. (A) Tyrosine-phosphorylated Stat3 and total Stat3 protein were analyzed in A549 and A549/TI 2 cells 24 hours after treatment with $0.1 \mu \mathrm{M}$ of poly(lactic-co-glycolic acid)-polyethylenimine nanoparticles loaded with siRNA (either Stat3 siRNA or scrambled siRNA). $\beta$-actin protein was used as the loading control. Cellular survival was assessed by 3-(4,5-dimethylthiazol-2-yl)-2,5-diphenyl tetrazolium bromide assay. (B) Cellular Stat I (red) and Stat3 (green) proteins were demonstrated with immunostaining and subsequent confocal microscopy at baseline and 24 hours after A549 and A549/TI 2 cells were treated with $0.1 \mu$ M of poly(lactic-coglycolic acid)-polyethylenimine nanoparticles loaded with Stat3 siRNA.

Notes: The nucleus is shown by 4',6-diamidino-2-phenylindole staining. Scale bar is $10 \mu \mathrm{m}$.

Abbreviations: NPs, nanoparticles; OD, optical density; PLGA-PEI-S3SI, poly(lactic-co-glycolic acid)-polyethylenimine nanoparticles loaded with signal transducer and activator of transcription-3 small interfering ribonucleic acid; PLGA-PEI-siRNA, poly(lactic-co-glycolic acid)-polyethylenimine nanoparticles loaded with small interfering ribonucleic acid; siRNA, small interfering ribonucleic acid; Stat I, signal transducer and activator of transcription-I; Stat3, signal transducer and activator of transcription-3.

The process that leads to NP entry into the cancer cells is mediated by the clathrin-dependent, caveolae-dependent, or clathrin/caveolae-independent pathway. ${ }^{30}$ NPs may influence the cells' biology after entering the cancer cells. Certain NPs may overcome chemoresistance through the inhibition of multidrug resistance-1 (MDR-1) function in MDR-1-overexpressing cancer cells. ${ }^{31}$ More PLGA-PEIOre TAX was taken up by both A549 and A549/T12 cells than free Oregon Green paclitaxel in the current study. Both cancer cells expressed a similar level of clathrin and caveolae (Figure S1A); however, paclitaxel-resistant A549/T12 cells did not express MDR-1 (Figure S1B). Because pretreatment with MDR-1 inhibitors (verapamil and GF120918) had an additive effect on cytotoxicity induced by PLGA-PEI-TAX in A549 cells only (Figure S1C), ${ }^{32}$ the mechanism that reverses chemoresistance demonstrated by PLGA-PEI-TAX is not limited to modulating MDR-1 function. It could be speculated that PLGA NPs act as a transportation shuttle that lets the cancer cells perform an endocytic uptake of drugs to bypass MDR- $1 .^{33}$ Afterwards, PLGA NPs act as an intracellular drug depot, which gradually uploads their drug payloads far away from the membrane-bound drug efflux to interact with their targets. ${ }^{14,33}$ Further studies are needed to confirm this assumption. 


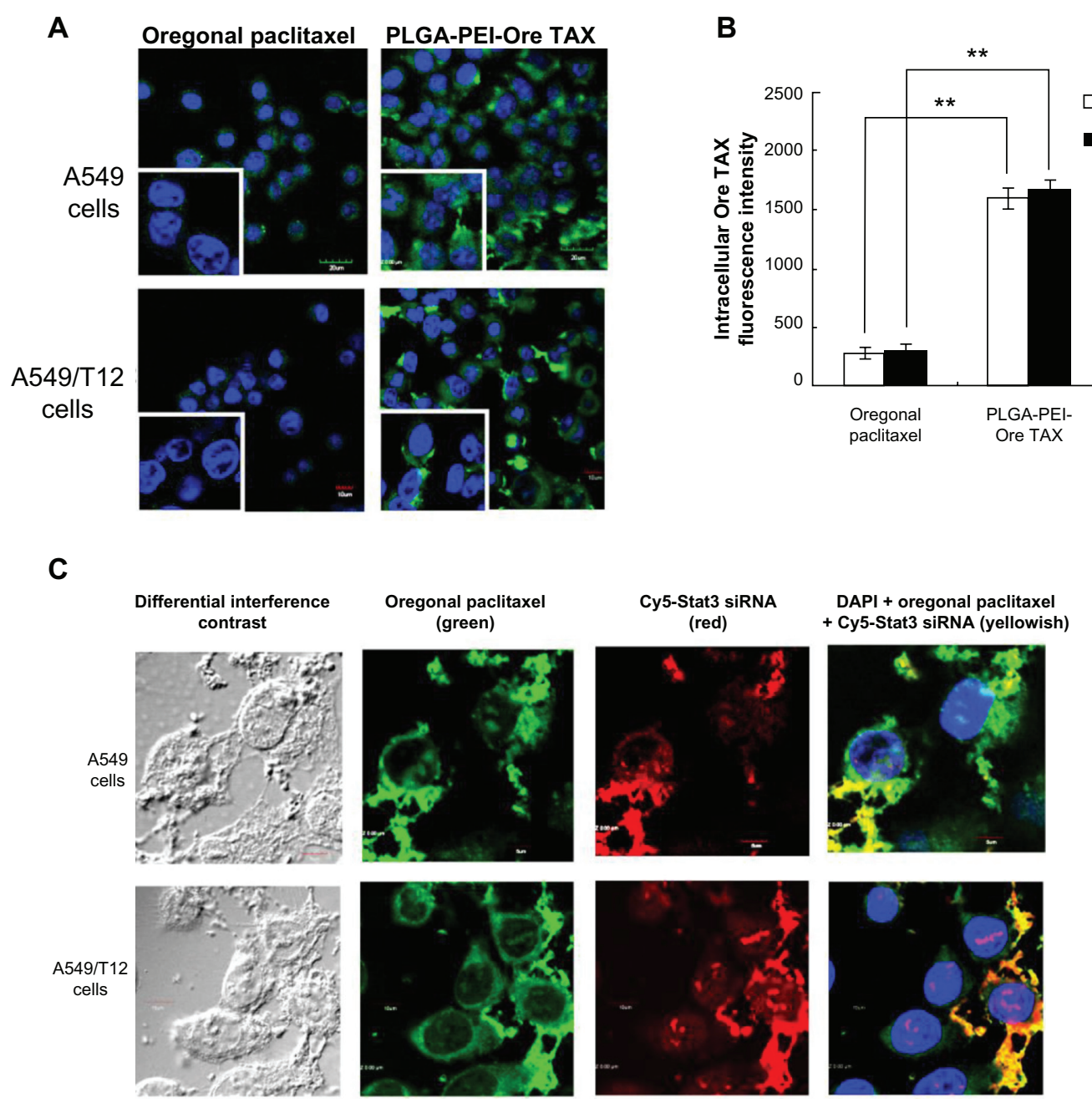

Figure 5 Uptake of poly(lactic-co-glycolic acid)-polyethylenimine nanoparticles loaded with Oregon Green paclitaxel (PLGA-PEI-Ore TAX) was higher in both A549 and A549/TI 2 cells compared to free Oregon Green paclitaxel. Demonstration of PLGA-PEI nanoparticles simultaneously delivering Oregon Green paclitaxel and cyanine-5labeled signal transducer and activator of transcription-3 small interfering ribonucleic acid was found in A549 and A549/TI2 cells. (A) Confocal microscopy was used to demonstrate intracellular accumulation of $62.5 \mathrm{nM}$ Oregon Green paclitaxel and $62.5 \mathrm{nM}$ PLGA-PEI-Ore TAX (green) 3 hours after treatment in A549 and A549/TI 2 cells. The left lower square of each panel (magnified cells) shows the different cellular uptake of Oregon Green paclitaxel and PLGA-PEI-Ore TAX in A549 and A549/TI2 cells. The nucleus is shown by 4',6-diamidino-2-phenylindole staining. Scale bar is $10 \mu \mathrm{m}$. (B) Intracellular Oregon Green paclitaxel was measured by fluorescence intensity in A549 and A549/TI 2 cells 3 hours after treatment with $62.5 \mathrm{nM}$ Oregon Green paclitaxel and PLGA-PEI-Ore TAX. (C) Confocal micrograph shows A549 and A549/TI 2 cells with different interference contrast and different fluorescent-enhanced image 3 hours after treatment with 62.5 nM PLGA-PEI nanoparticles loaded with Oregon Green paclitaxel and cyanine-5-labeled signal transducer and activator of transcription-3 small interfering ribonucleic acid.

Note: Scale bar is either $5 \mu \mathrm{m}$ or $10 \mu \mathrm{m}$.

Abbreviations: Cy5-Stat3 siRNA, cyanine-5-labeled signal transducer and activator of transcription-3 small interfering ribonucleic acid; DAPI, 4',6-diamidino-2-phenylindole; Ore TAX, Oregon Green paclitaxel; PLGA-PEI-Ore TAX, poly(lactic-co-glycolic acid)-polyethylenimine nanoparticles loaded with Oregon Green paclitaxel.

PLGA NPs start to escape the endosomal compartment 4 hours after treatment. ${ }^{34}$ PLGA-PEI NPs may have a stronger ability to escape the acidic $\mathrm{pH}$ of the endosome than PLGA NPs alone since PEI dissolves more readily in aqueous buffers and has a proton sponge effect. ${ }^{20}$ Compared to paclitaxel, Stat3 siRNA was more rapidly released from PLGA-PEI-TAX-S3SI within 24 hours. It was found that 3 hours after A549 and A549/T12 cells were treated with PLGA-PEI-Ore TAX-Cy5-S3SI, some Cy5-Stat3 siRNA was released from the PLGA-PEI NPs, but most of the Oregon Green paclitaxel was still bound to the NPs. Hence,
Stat3 siRNA may be released first to decrease expression of Stat3 and reduce cellular resistance to paclitaxel before paclitaxel is uploaded from PLGA-PEI-TAX-S3SI NPs in cancer cells. The released paclitaxel then kills the cancer cells effectively.

PLGA-PEI-TAX induced more microtubule aggregation than free paclitaxel in both A549 and A549/T12 cells. This might be due to the greater uptake of PLGA-PEI-TAX by cancer cells. Tubulin aggregation was attenuated in A549/ T12 cells compared to that in parental A549 cells when Stat 3 was downregulated by PLGA-PEI-TAX-S3SI. Activation of 

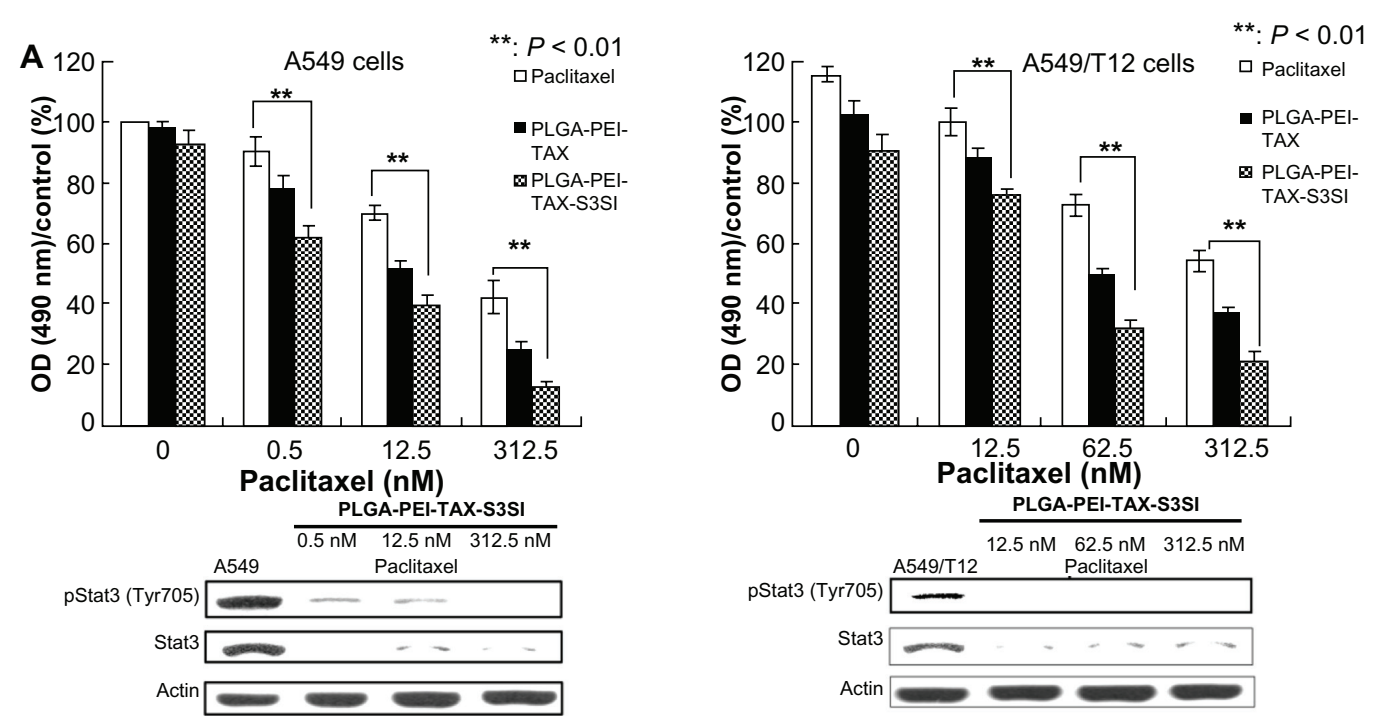

B

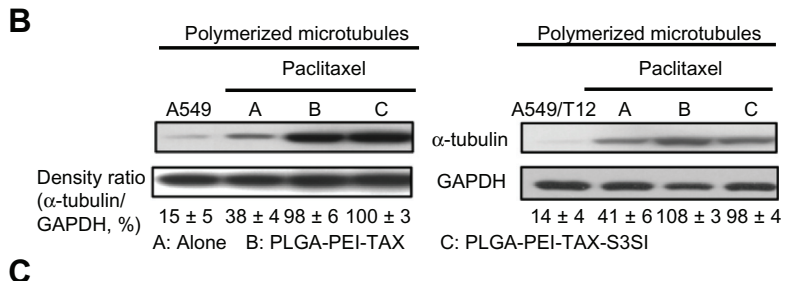

C
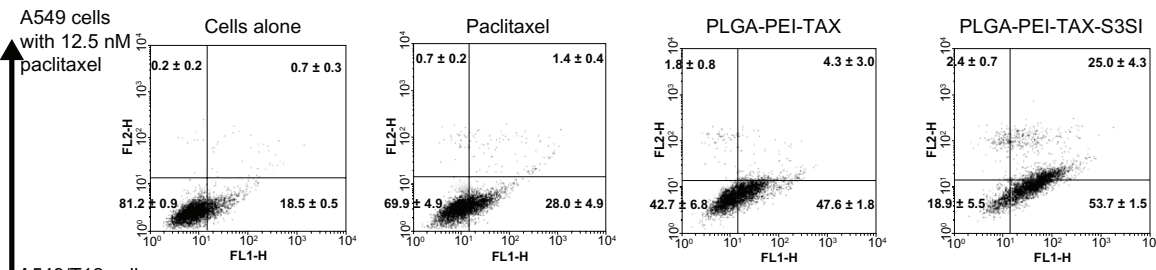

A549/T12 cells
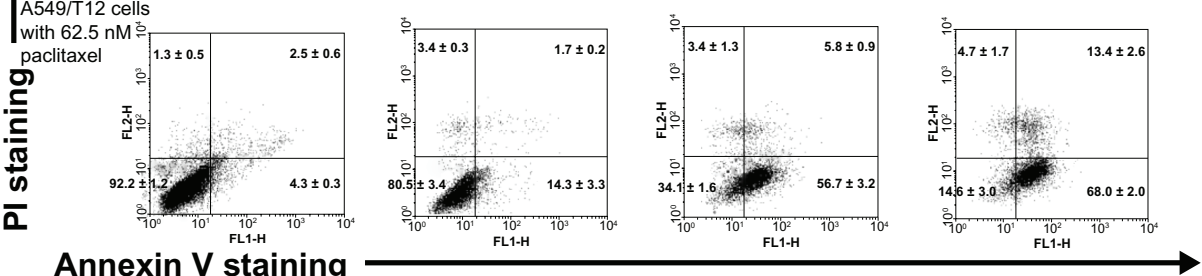

Figure 6 Both A549 and A549/T I2 cells were more sensitive to poly(lactic-co-glycolic acid)-polyethylenimine nanoparticles loaded with paclitaxel and signal transducer and activator of transcription-3 (Stat3) small interfering ribonucleic acid (PLGA-PEI-TAX-S3SI). (A) Tyrosine-phosphorylated Stat3 and total Stat3 proteins were blotted 24 hours after A549 and A549/TI 2 cells were treated with PLGA-PEI-TAX-S3SI. $\beta$-actin protein was used as the loading control. Cellular survival was assessed by 3-(4,5-dimethylthiazol2-yl)-2,5-diphenyl tetrazolium bromide assay after 48 hours of treatment with PLGA-PEI-TAX-S3SI and PLGA-PEI-TAX at various dosages $(0.5 \mathrm{nM}, 12.5 \mathrm{nM}$, and 3 I2.5 nM in A549 cells; $12.5 \mathrm{nM}, 62.5 \mathrm{nM}$, and $312.5 \mathrm{nM}$ in A549/TI2 cells). (B) Polymerized tubulin was observed 24 hours after A549 cells were treated with $12.5 \mathrm{nM}$ paclitaxel, PLGA-PEI-TAX, and PLGA-PEI-TAX-S3SI, respectively. The same treatment was performed in A549/TI2 cells with a higher concentration (62.5 nM). Glyceraldehyde 3-phosphate dehydrogenase protein was used as the loading control. The band density ratio ( $\alpha$-tubulin to glyceraldehyde 3-phosphate dehydrogenase) represents data from three experiments (mean \pm standard deviation). (C) Flow cytometric analysis of A549 cells treated with $12.5 \mathrm{nM}$ paclitaxel, PLGA-PEI-TAX, and PLGA-PEI-TAX-S3SI for 24 hours, respectively. The same experiment with higher concentration ( $62.5 \mathrm{nM})$ was performed in A549/TI2 cells.

Notes: The scatter plot of FLI-H (X-scale) versus FL2-H (Y-scale) indicates Annexin $\mathrm{V}$ staining and propidium iodine staining. The experiment was repeated three times, and data are shown as mean \pm standard deviation.

Abbreviations: GAPDH, glyceraldehyde 3-phosphate dehydrogenase; OD, optical density; PI, propidium iodine; PLGA-PEI-TAX, poly(lactic-co-glycolic acid)-polyethylenimine nanoparticles loaded with paclitaxel; PLGA-PEI-TAX-S3SI, poly(lactic-co-glycolic acid)-polyethylenimine nanoparticles loaded with paclitaxel and signal transducer and activator of transcription-3 small interfering ribonucleic acid; Stat3, signal transducer and activator of transcription-3.

Stat3 has been implicated in antagonizing stathmin-induced microtubule depolymerization..$^{35}$ The active nonphosphorylated form of stathmin is higher in A549/T12 cells harboring the $\alpha$-tubule mutation compared to parental A549 cells. $^{21}$ Therefore, Stat 3 suppression in A549/T12 cells is likely to enhance the stathmin-induced microtubule depolymerization in A549/T12 cells and could result in less tubulin aggregation after paclitaxel treatment. Inhibition of Stat 3 activation decreases cell viability, increases apoptosis, and reduces cellular resistance to paclitaxel. ${ }^{7}$ Thus, PLGA-PEI-TAX-S3SI 
treatment effectively leads both cancer cells towards apoptosis and early necrosis.

The diameter of PLGA-PEI-TAX in the current study was about $300 \mathrm{~nm}$, as measured by DLS. Although experiments from animal studies suggest that the optimal NP cancer therapeutics should range from $10-150 \mathrm{~nm},{ }^{36} 130-750-\mathrm{nm}$ NPs are considered suitable for delivery of therapeutic modalities to the lungs. ${ }^{37}$ Patil and Panyam reported the formulation of a biotin-functionalized PLGA-PEI nanovector $(240 \mathrm{~nm})$ loaded with the combination of paclitaxel and P-glycoproteintargeted siRNA. They demonstrated that this nanovector had significant cytotoxicity in vivo through the intravenous route. ${ }^{38}$ They found a $15 \%$ and $20 \%$ release of paclitaxel and siRNA, respectively, in the first 24 hours. A sustained release of up to $25 \%$ for paclitaxel and $45 \%$ for siRNA was observed during the first 3 days. ${ }^{38}$ The release profile of paclitaxel and siRNA from PLGA-PEI-TAX-S3SI in the current study was better (Figure 2B-D). Further studies testing the activity and safety in vivo are needed to detect whether Stat3 siRNA carried by PLGA-PEI-TAX-S3SI will be degraded in blood or induce immune reaction in vivo.

\section{Conclusion}

A solvent evaporation and stabilizer-free method was developed to synthesize the PLGA-PEI-TAX-S3SI nanocomplex, which can be taken up by cancer cells to downregulate Stat 3 protein and kill lung cancer cells effectively. PLGA-PEI NPs may provide a platform for the integration of anticancer drugs and siRNA to improve cancer treatment.

\section{Acknowledgments}

The National Science Council (Grant NSC-97-2314-B006-013-MY3 and NSC100-2120-M-006-002) and the Department of Health (Grant DOH-100-TD-PB-111-TM-014, DOH101-TD-B-111-102, and DOH101-TD-C-111-003) supported this study.

\section{Disclosure}

The authors report no conflicts of interest in this work.

\section{References}

1. Janku F, Stewart DJ, Kurzrock R. Targeted therapy in non-small-cell lung cancer - is it becoming a reality? Nat Rev Clin Oncol. 2010;7(7): 401-414.

2. Scagliotti GV. Potential role of multi-targeted tyrosine kinase inhibitors in non-small-cell lung cancer. Ann Oncol. 2007;18(Suppl 10):32-41.

3. Darnell JE Jr. Stats and gene regulation. Science. 1997;277(5332): $1630-1635$.

4. Jing N, Tweardy DJ. Targeting Stat3 in cancer therapy. Anticancer Drugs. 2005;16(6):601-607.
5. Gritsko T, Williams A, Turkson J, et al. Persistent activation of Stat3 signaling induces survivin gene expression and confers resistance to apoptosis in human breast cancer cells. Clin Cancer Res. 2006;12(1): $11-19$.

6. Song L, Turkson J, Karras JG, Jove R, Haura EB. Activation of Stat3 by receptor tyrosine kinases and cytokines regulates survival in human non-small cell carcinoma cells. Oncogene. 2003;22(27):4150-4165.

7. Ikuta K, Takemura K, Kihara M, et al. Overexpression of constitutive signal transducer and activator of transcription 3 mRNA in cisplatinresistant human non-small cell lung cancer cells. Oncol Rep. 2005; 13(2):217-222.

8. Kawakami S, Hashida M. Targeted delivery systems of small interfering RNA by systemic administration. Drug Metab Pharmacokinet. 2007; 22(3):142-151.

9. Putral LN, Gu W, McMillan NA. RNA interference for the treatment of cancer. Drug News Perspect. 2006;19(6):317-324.

10. Wang Y, Gao S, Ye WH, Yoon HS, Yang YY. Co-delivery of drugs and DNA from cationic core-shell nanoparticles self-assembled from a biodegradable copolymer. Nat Mater. 2006;5(10):791-796.

11. Devalapally H, Duan Z, Seiden MV, Amiji MM. Modulation of drug resistance in ovarian adenocarcinoma by enhancing intracellular ceramide using tamoxifen-loaded biodegradable polymeric nanoparticles. Clin Cancer Res. 2008;14(10):3193-3203.

12. Jain RA. The manufacturing techniques of various drug loaded biodegradable poly(lactide-co-glycolide acid) (PLGA) devices. Biomaterials. 2000;21(23):2475-2490.

13. Panyam J, Labhasetwar V. Biodegradable nanoparticles for drug and gene delivery to cells and tissue. Adv Drug Deliv Rev. 2003;55(3): 329-347.

14. Panyam J, Labhasetwar V. Sustained cytoplasmic delivery of drugs with intracellular receptors using biodegradable nanoparticles. Mol Pharm. 2004;1(1):77-84.

15. Bilati U, Allemann E, Doelker E. Development of a nanoprecipitation method intended for the entrapment of hydrophilic drugs into nanoparticles. Eur J Pharm Sci. 2005;24(1):67-75.

16. Cui W, Bei J, Wang S, et al. Preparation and evaluation of poly(Llactide-co-glycolide) (PLGA) microbubbles as a contrast agent for myocardial contrast echocardiography. J Biomed Mater Res B Appl Biomater. 2005;73(1):171-178.

17. Cheng FY, Wang PH, Su CH, et al. Stabilizer-free poly(lactideco-glycolide) nanoparticles for multimodal biomedical probes. Biomaterials. 2008;29(13):2104-2112.

18. Cheng FY, Su CH, Wu PC, Yeh CS. Multifunctional polymeric nanoparticles for combined chemotherapeutic and near-infrared photothermal cancer therapy in vitro and in vivo. Chem Commun (Camb). 2010; 46(18):3167-3169.

19. Yuan X, Naguib S, Wu Z. Recent advances of siRNA delivery by nanoparticles. Expert Opin Drug Deliv. 2011;8(4):521-536.

20. Yezhelyev MV, Qi L, O'Regan RM, Nie S, Gao X. Proton-sponge coated quantum dots for siRNA delivery and intracellular imaging. J Am Chem Soc. 2008;130(28):9006-9012.

21. Martello LA, Verdier-Pinard P, Shen HJ, et al. Elevated levels of microtubule destabilizing factors in a Taxol-resistant/dependent A549 cell line with an alpha-tubulin mutation. Cancer Res. 2003;63(6): 1207-1213.

22. Hsieh CC, Kuo YH, Kuo CC, et al. Chamaecypanone C, a novel skeleton microtubule inhibitor, with anticancer activity by trigger caspase 8-Fas/ FasL dependent apoptotic pathway in human cancer cells. Biochem Pharmacol. 2010;79(9):1261-1271.

23. Meng H, Liong M, Xia T, et al. Engineered design of mesoporous silica nanoparticles to deliver doxorubicin and P-glycoprotein siRNA to overcome drug resistance in a cancer cell line. ACS Nano. 2010;4(8): 4539-4550.

24. Dong Y, Feng SS. In vitro and in vivo evaluation of methoxy polyethylene glycol-polylactide (MPEG-PLA) nanoparticles for small-molecule drug chemotherapy. Biomaterials. 2007;28(28): 4154-4160.

25. Zhang X, Li Y, Chen X, et al. Synthesis and characterization of the paclitaxel/MPEG-PLA block copolymer conjugate. Biomaterials. 2005; 26(14):2121-2128. 
26. Gaucher G, Marchessault RH, Leroux JC. Polyester-based micelles and nanoparticles for the parenteral delivery of taxanes. J Control Release. 2010;143(1):2-12.

27. Kim YH, Park JH, Lee M, Kim YH, Park TG, Kim SW. Polyethylenimine with acid-labile linkages as a biodegradable gene carrier. J Control Release. 2005;103(1):209-219.

28. Gwak SJ, Kim BS. Poly(lactic-co-glycolic acid) nanosphere as a vehicle for gene delivery to human cord blood-derived mesenchymal stem cells: comparison with polyethylenimine. Biotechnol Lett. 2008;30(7): 1177-1182.

29. PatilY, Panyam J. Polymeric nanoparticles for siRNA delivery and gene silencing. Int J Pharm. 2009;367(1-2):195-203.

30. Sahay G, Alakhova DY, Kabanov AV. Endocytosis of nanomedicines. $J$ Control Release. 2010;145(3):182-195.

31. Dong X, Mattingly CA, Tseng MT, et al. Doxorubicin and paclitaxelloaded lipid-based nanoparticles overcome multidrug resistance by inhibiting P-glycoprotein and depleting ATP. Cancer Res. 2009;69(9): 3918-3926.

32. Mayur YC, Peters GJ, Prasad VV, Lemo C, Sathish NK. Design of new drug molecules to be used in reversing multidrug resistance in cancer cells. Curr Cancer Drug Targets. 2009;9(3):298-306.
33. Hu CM, Zhang L. Therapeutic nanoparticles to combat cancer drug resistance. Curr Drug Metab. 2009;10(8):836-841.

34. Cartiera MS, Johnson KM, Rajendran V, Caplan MJ, Saltzman WM. The uptake and intracellular fate of PLGA nanoparticles in epithelial cells. Biomaterials. 2009;30(14):2790-2798.

35. Ng DC, Lin BH, Lim CP, et al. Stat3 regulates microtubules by antagonizing the depolymerization activity of stathmin. $J$ Cell Biol. 2006;172(2):245-257.

36. Davis ME, Chen ZG, Shin DM. Nanoparticle therapeutics: an emerging treatment modality for cancer. Nat Rev Drug Discov. 2008;7(9): 771-782.

37. Azarmi S, Roa WH, Lobenberg R. Targeted delivery of nanoparticles for the treatment of lung diseases. Adv Drug Deliv Rev. 2008;60(8): 863-875.

38. Patil YB, Swaminathan SK, Sadhukha T, Ma L, Panyam J. The use of nanoparticle-mediated targeted gene silencing and drug delivery to overcome tumor drug resistance. Biomaterials. 2010;31(2):358-365. 


\section{Supplementary figure}

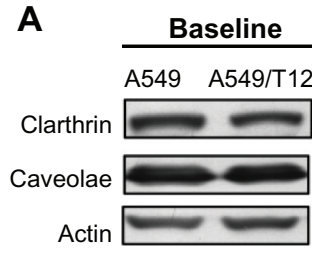

C
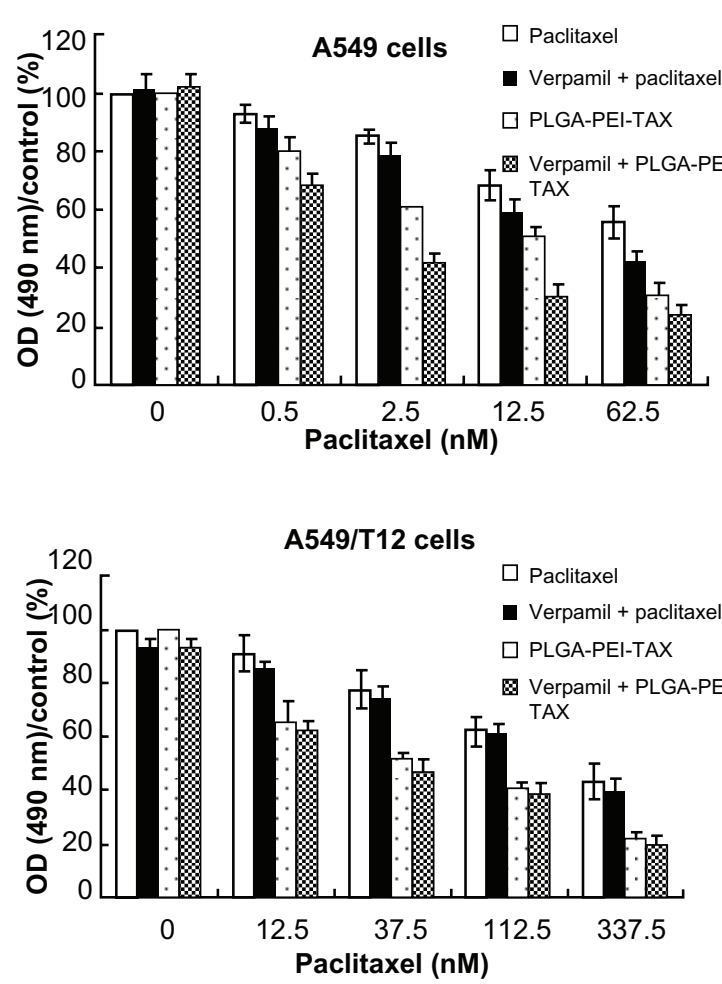

B

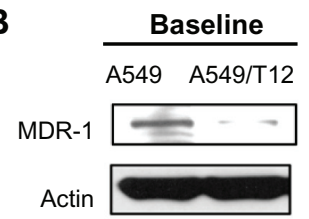

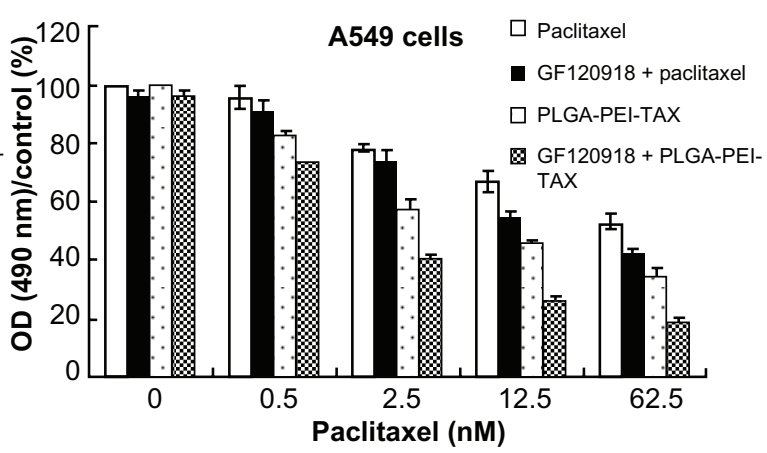

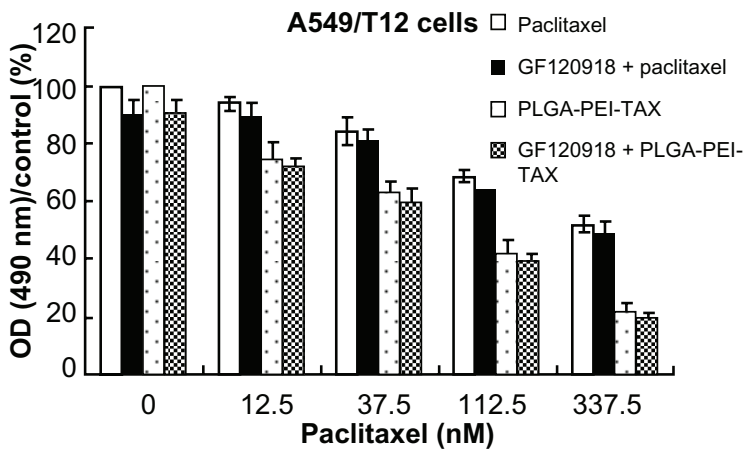

Figure SI Multidrug resistance-I (MDR-I), clathrin, and caveolae protein expression in A549 and A549/TI2 cells and pretreatment with MDR-I inhibitors influenced the cellular survival of A549 and A549/TI2 cells treated with paclitaxel and poly(lactic-co-glycolic acid)-polyethylenimine nanoparticles loaded with paclitaxel. (A) Analysis of baseline clathrin and caveolae protein expression in A549 and A549/TI2 cells. $\beta$-actin protein was used as the loading control. (B) Analysis of baseline MDR-I protein expression in A549 and A549/TI2 cells. (C) Cellular survival of A549 and A549/TI2 cells was assessed by 3-(4,5-dimethylthiazol-2-yl)-2,5-diphenyl tetrazolium bromide assay after 48 hours of treatment with paclitaxel and poly(lactic-co-glycolic acid)-polyethylenimine nanoparticles loaded with paclitaxel, with and without pretreatment of MDR-I inhibitors (verapamil and GFI209/8).

Abbreviations: MDR-I, multidrug resistance-I; OD, optical density; PLGA-PEI-TAX, poly(lactic-co-glycolic acid)-polyethylenimine nanoparticles loaded with paclitaxel.

International Journal of Nanomedicine

Dovepress

\section{Publish your work in this journal}

The International Journal of Nanomedicine is an international, peerreviewed journal focusing on the application of nanotechnology in diagnostics, therapeutics, and drug delivery systems throughout the biomedical field. This journal is indexed on PubMed Central, MedLine, CAS, SciSearch ${ }^{\circledR}$, Current Contents ${ }^{\circledR} /$ Clinical Medicine,
Journal Citation Reports/Science Edition, EMBase, Scopus and the Elsevier Bibliographic databases. The manuscript management system is completely online and includes a very quick and fair peer-review system, which is all easy to use. Visit http://www.dovepress.com/ testimonials.php to read real quotes from published authors. 